\title{
Asynchrony and Dyspnea
}

\author{
Richard D Branson MSc RRT FAARC, Thomas C Blakeman MSc RRT, \\ and Bryce RH Robinson MD
}

\author{
Introduction \\ Defining Asynchrony \\ Flow Asynchrony, Flow Mismatch, and Flow Starvation \\ Missed Triggers \\ Auto-triggering \\ Double-Triggering \\ Reverse Triggering \\ Mode Asynchrony \\ Premature and Prolonged Cycling \\ Identifying Asynchrony \\ Automated Detection of Asynchrony \\ Incidence of Asynchrony and Outcomes \\ Invasive Ventilation \\ Asynchrony and Outcome \\ Asynchrony in NIV \\ Asynchrony and Outcome in NIV \\ Asynchrony and Sleep \\ Unresolved Issues \\ Asynchrony and Respiratory Muscle Dysfunction \\ Asynchrony and Dyspnea \\ Summary
}

\begin{abstract}
Patient-ventilator synchrony and patient comfort are assumed to go hand in hand, yet few studies provide support for this common sense idea. In reality, synchrony between the patient and ventilator is complex and can be affected by the ventilator settings, type of ventilator, patient-ventilator interface, and sedation. Inspections of airway pressure and flow waveforms are reliable methods for detecting asynchrony, and automated detection seems accurate. A number of types of asynchronies have been defined, and asynchrony during invasive and noninvasive ventilation have different calling cards. There is a clear association between asynchrony, ventilator-induced diaphragmatic dysfunction, and duration of mechanical ventilation. Whether these are cause and effect or simply associated remains to be determined. Key words: synchrony; dyspnea; asynchrony; respiratory muscles; noninvasive ventilation. [Respir Care 2013;58(6):973-986. (C) 2013 Daedalus Enterprises]
\end{abstract}

The authors are affiliated with the Division of Trauma and Critical Care, Department of Surgery, University of Cincinnati, Cincinnati, Ohio.

Mr Branson presented a version of this paper at the 51st RESPIRATORY CARE Journal Conference, "Adult Mechanical Ventilation in Acute Care: Issues and Controversies," held September 7 and 8, 2012, in St Petersburg, Florida.

Mr Branson has disclosed relationships with Advanced Circulatory Systems, Ikaria, General Electric, Impact Instrumentation, CareFusion, Ham-

\footnotetext{
ilton Medical, Newport Medical Instruments, Ikaria, Covidien, and Breathe Technologies.
}

Correspondence: Richard D Branson MSc RRT FAARC, Division of Trauma and Critical Care, Department of Surgery, University of Cincinnati, 231 Albert Sabin Way, Cincinnati OH 45267-0558. E-mail: richard.branson@uc.edu.

DOI: $10.4187 /$ respcare. 02507 


\section{Introduction}

Mechanical ventilation is one of the most common procedures implemented in the ICU. ${ }^{1}$ The goals of mechanical ventilation are to improve gas exchange, reduce the work of breathing, and improve patient comfort. The interaction between the patient and the ventilator can facilitate or obfuscate the latter two goals. During the early era of positive-pressure ventilation, what is known commonly today as patient-ventilator synchrony was typically recognized only in its extreme as the patient "bucking" or "fighting" the ventilator. ${ }^{2}$ In recent years, technology and clinical research have allowed a more detailed analysis of patient-ventilator interaction and fueled our understanding of patient-ventilator synchrony. The importance of patientventilator synchrony can be underscored by the emphasis placed in these pages in the last 2 years..$^{3-10}$

While avoiding asynchrony and striving for synchrony appears to be a worthwhile goal, there remain a number of unanswered questions. Asynchrony appears to be associated with longer duration of ventilatory support, but there is no clear cause and effect. The use of ventilator flow and pressure waveforms allow detection of asynchrony, but the impact on patient comfort and the sensation of dyspnea has not been well defined. Respiratory muscle dysfunction associated with critical illness and mechanical ventilation is not nearly as well understood as ventilator-induced lung injury. One missing piece is the contribution of patientventilator asynchrony to diaphragmatic dysfunction. Most of the early work on patient-ventilator asynchrony was accomplished during invasive ventilation, but there are unique issues related to noninvasive ventilation (NIV) that have become apparent. ${ }^{10}$ This paper will explore emerging and unresolved issues related to patient-ventilator synchrony and dyspnea.

\section{Defining Asynchrony}

There are a number of descriptions of asynchrony. Table 1 lists the common types identified in the literature.

\section{Flow Asynchrony, Flow Mismatch, and Flow Starvation}

While the recent flurry of activity has revolved around triggering and timing issues, the role of flow asynchrony during volume ventilation was detailed by Marini and colleagues in a series of papers in the mid-1980s..$^{11-13}$ They noted that the fixed flow and flow pattern of volume control in patient-triggered breaths were inflexible with respect to patient demand. In a study of normal subjects they found that changing the sensitivity from $-2 \mathrm{~cm} \mathrm{H}_{2} \mathrm{O}$ to $-5 \mathrm{~cm} \mathrm{H}_{2} \mathrm{O}$ increased the work of breathing by $34 \%$. When the minute ventilation $\left(\dot{\mathrm{V}}_{\mathrm{E}}\right)$ was driven by increas-
Table 1. Types of Asynchrony

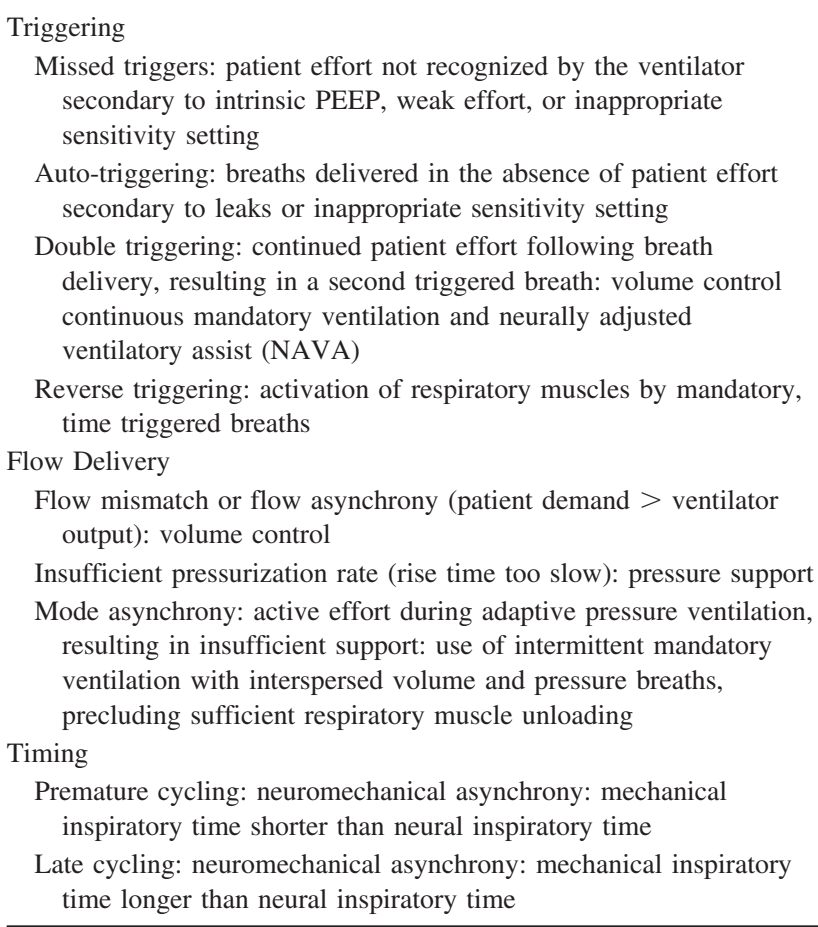

ing inspired carbon dioxide from $12 \mathrm{~L} / \mathrm{min}$ to $24 \mathrm{~L} / \mathrm{min}$, the work of breathing rose by $>300 \%$. The main determinant of work of breathing was the set flow. When flow was reduced from $82 \mathrm{~L} / \mathrm{min}$ to $40 \mathrm{~L} / \mathrm{min}$, the work of breathing increased by $>50 \%$. Even at the most favorable sensitivity and flow settings the subjects continued to expend 33-50\% of the energy required for passive inflation. These authors were among the first to suggest that inappropriate selection of the ventilatory mode or flow settings might contribute to respiratory muscle fatigue and dyspnea. These experiments were accomplished using the $\mathrm{Pu}$ ritan Bennett MA-1 and the Servo 900C, but the basic tenets are still true with modern ICU ventilators.

MacIntyre and others showed that decreasing the set flow by $50 \%$ during volume ventilation resulted in significant increases in pressure-time product and esophageal pressure swings in 16 patients. They were able to achieve a pressure-time product of $>5 \mathrm{~cm} \mathrm{H}_{2} \mathrm{O} / \mathrm{s}$ in 10 of the 16 patients. They noted that increasing the flow during volume ventilation reduced patient effort, but that inspiratory time was significantly shortened. The use of pressure ventilation was found to be more effective at reducing the indices of work of breathing in patients with vigorous respiratory efforts. ${ }^{14}$ It is important to note that the tidal volumes $\left(\mathrm{V}_{\mathrm{T}}\right)$ used in this trial averaged nearly $750 \mathrm{~mL}$, and the advantage of pressure control over volume control may not hold true with $\mathrm{V}_{\mathrm{T}}$ controlled at $6 \mathrm{~mL} / \mathrm{kg}$ or less. 

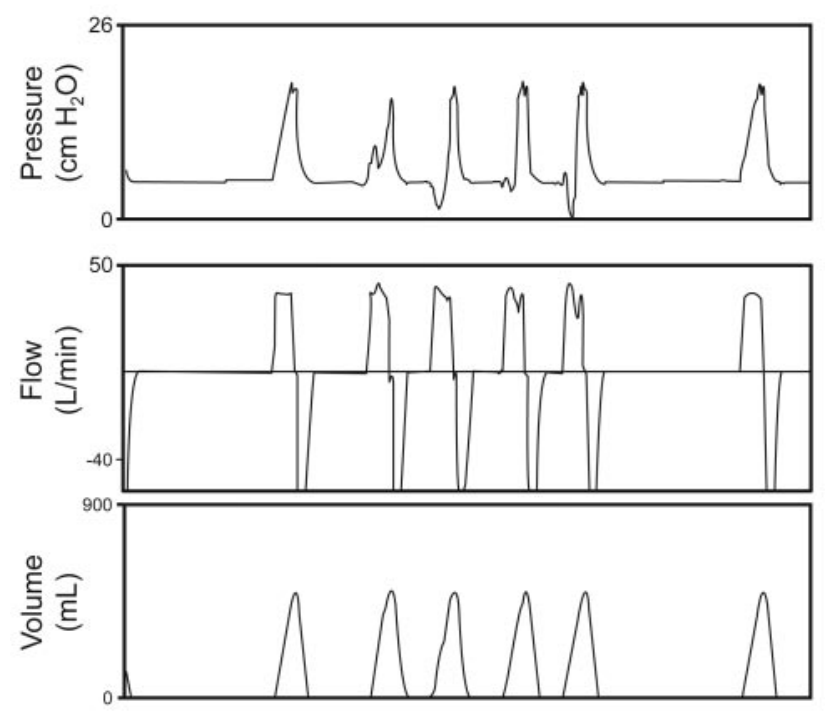

Fig. 1. Volume control continuous mandatory ventilation demonstrating a mandatory breath delivered without patient effort, followed by 2 breaths where patient demand exceeds the set ventilator flow, depicting the classic alteration in the pressure waveform followed by a second mandatory breath.

Tobin and others described the importance of eliminating the change in the shape of the airway pressure graphic during triggered mandatory breaths, when compared to a passive breath. ${ }^{15}$ The scalloped out portion of the pressure waveform during a patient-triggered volume breath is a well recognized sign of flow asynchrony (Fig. 1). Interestingly, increasing inspiratory flow during a volume breath can reduce the work of breathing, but is associated with a shorter inspiratory time and an alteration in the patient's respiratory frequency. The effect of the ventilator inspiratory time on the respiratory frequency is a complicating factor when adjusting flow to reduce flow asynchrony. ${ }^{16}$

\section{Missed Triggers}

Missed triggers, also called ineffective triggering or trigger asynchrony, refers to patient efforts that are not sensed by the ventilator. ${ }^{17,18}$ Missed triggers can be the result of inappropriate trigger sensitivity setting, respiratory muscle weakness, diminished respiratory drive, dynamic hyperinflation, or a combination of these factors. Dynamic hyperinflation associated with large $\mathrm{V}_{\mathrm{T}}$ during pressure support ventilation (PSV) in patients with elevated airways resistance and normal pulmonary compliance (eg, COPD) are the most often described reason for missed triggers. ${ }^{17-23}$ Missed triggers can also occur during volume control ventilation.

Missed triggers are easily identified by inspection of the expiratory flow waveform (Fig. 2). A positive deflection in expiratory flow, followed by an increase in expiratory
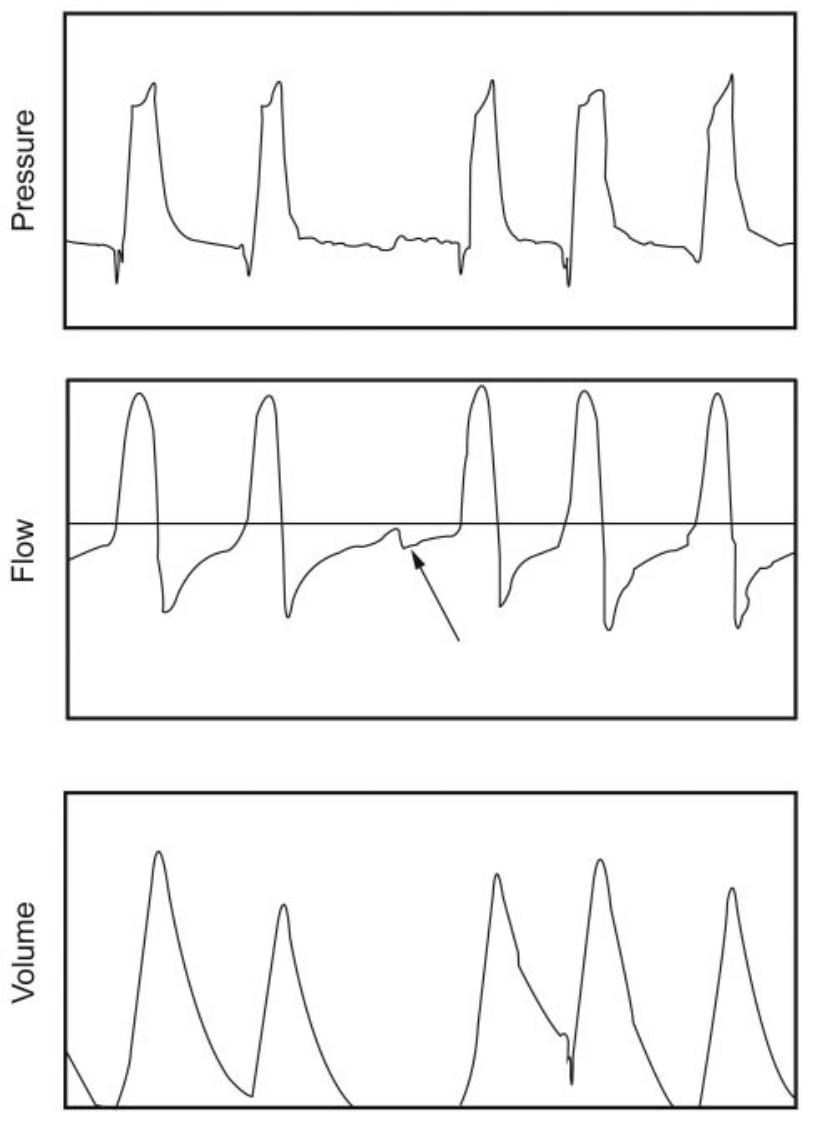

Fig. 2. Example of a missed trigger during pressure control ventilation. The arrow demonstrates the positive flow deflection that is the hallmark sign of a missed trigger.

flow without delivery of a breath from the ventilator, can be detected on the waveform display of most ventilators. The pressure tracing is rarely altered, as that change would be detected by the ventilator and a breath delivered. This "notch" in the expiratory flow may be described as 2 expiratory periods. The gold standard for detecting missed triggers is the use of esophageal monitoring or measurement of the electrical activity of the diaphragm. ${ }^{17,18}$ However, both methods require placement of an esophageal catheter, which is not used in routine care.

\section{Auto-triggering}

Auto-triggering is delivery of a breath that is neither scheduled based on the set respiratory frequency nor initiated by the patient (Fig. 3). Esophageal monitoring is the gold standard here as well, as a breath delivered in the absence of diaphragmatic contraction is clearly auto-triggered. Auto-triggering can be caused by leaks in the patient-ventilator system or improper setting of the sensitivity (too sensitive). Auto-triggering is one of the most 

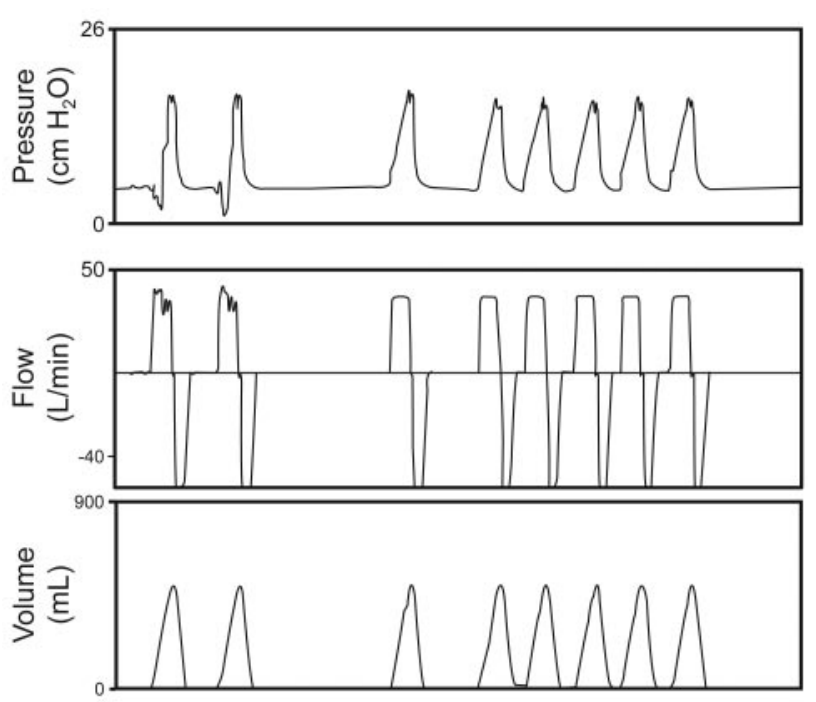

Fig. 3. An example of auto-triggering caused by a leak in the system. During volume control ventilation, mandatory breaths are followed by a series of auto-triggered breaths, and then correction of the sensitivity and return to normal ventilation.

common types of asynchrony during NIV. However, autotriggering may be caused by condensate in the circuit, resulting in transient changes in flow, cardiac oscillations, ${ }^{24-32}$ and improperly placed pacing wires. ${ }^{33}$

Auto-triggering during invasive ventilation commonly occurs in the patient with normal respiratory mechanics and a bounding pulse (large stroke volume). The change in intrathoracic pressure creates a change in the airway pressure and flow signal. Critically, this may also occur in the patient with a devastating brain injury and normal lung mechanics. ${ }^{24-32}$ The literature demonstrates a number of cases of auto-triggering in patients with brain death, leading to inappropriate delays in organ donation. ${ }^{24-32}$ Autotriggering can result in sudden respiratory alkalosis and worsen intrinsic PEEP and cardiac embarrassment. Clinically, if auto-triggering is suspected, disconnecting the patient from the ventilator briefly allows inspection of the patient's innate ventilatory rate. Similarly, if auto-triggering occurs during a spontaneous breathing trial, clinicians may be misled into believing that the trial has failed.

Auto-triggering is the most common type of asynchrony during NIV, resulting from leaks around the interface. ${ }^{34,35}$ Carteaux et al found that auto-triggering was the rule rather than the exception when using ICU ventilators to ventilate a lung model with a variable leak. They found that the NIV option of these ventilators improved the magnitude of auto-triggering, but that the use of devices built to work with a leak performed best. ${ }^{34}$ Prinianakis found reciprocal findings in a comparison of an ICU ventilator and noninvasive ventilator during support of intubated patients. ${ }^{36}$ The NIV device had a shorter trigger delay and fewer missed trig-

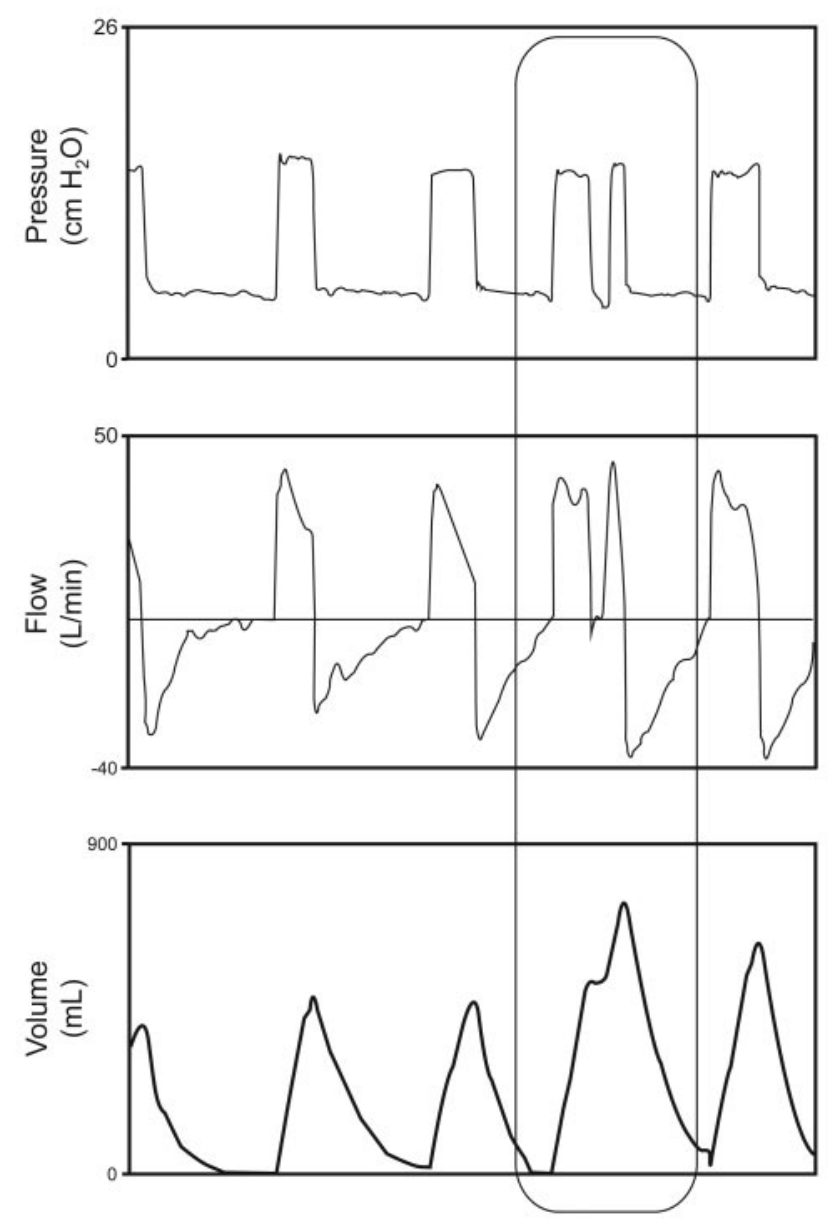

Fig. 4. An example of double triggering. Patient demand continues beyond the set inspiratory time, resulting in triggering of a second mandatory breath during the same patient effort.

gers than the ICU ventilator, but also had 5 times as many auto-trigger events.

\section{Double-Triggering}

Hill and Pearl described double triggering as 2 consecutive inspirations occurring within an interval of less than half of the mean inspiratory time. ${ }^{24}$ Double triggering (Fig. 4) typically occurs during volume control continuous mandatory ventilation, but has been described during neurally adjusted ventilatory assist. ${ }^{37,38}$ During PSV with a high flow termination criterion, double triggering is also possible. Double triggering can be caused by aggressive patient efforts in conjunction with small $\mathrm{V}_{\mathrm{T}}$ and short inspiratory times. Specifically, if respiratory drive is high, set $\mathrm{V}_{\mathrm{T}}$ is in lieu of patient demand, and inspiratory time is shorter than neural inspiratory time, the mandatory breath will be delivered, followed by a second breath as the trigger threshold is surpassed. In the presence of a true double trigger, the second breath usually achieves a higher peak 
inspiratory pressure, as the breaths are stacked. Double triggering may result in overinflation and pulmonary barotrauma/volutrauma.

\section{Reverse Triggering}

Akoumianaki and colleagues have recently described "reverse triggering" as a unique type of neuromechanical asynchrony. ${ }^{39}$ In 8 heavily sedated patients with ARDS they found that 7 patients had entrainment of neural breaths within mandatory breaths. This entrainment occurred at a ratio of 1:1 up to 1:3. Entrainment has been described previously, but this is the first description in heavily sedated patients receiving volume control ventilation. ${ }^{40-42}$ While these findings are preliminary, it is possible that entrainment may result in pliometric contractions of the diaphragm. Pliometric contractions are associated with cytokine release and damage to muscle fibers. Clinically speaking, this might result in alterations in measured plateau pressures, increased oxygen consumption, and hemodynamic instability. ${ }^{43}$ This may play a role in ventilatorinduced diaphragmatic dysfunction.

\section{Mode Asynchrony}

Mode asynchrony has been described during synchronized intermittent mandatory ventilation (SIMV) ${ }^{12,44}$ and volume support ventilation. ${ }^{45}$ Marini and colleagues studied the work of breathing in 12 acutely ill patients during SIMV, and found that the frequency and $\mathrm{V}_{\mathrm{T}}$ of spontaneous breaths increased at lower levels of mechanical ventilation. As the mandatory breath rate was reduced, inspiratory work and pressure-time product increased progressively for both breath types. They concluded that the respiratory muscles remained active at all levels of ventilator assistance. Work per liter increased linearly with $\dot{\mathrm{V}}_{\mathrm{E}}$, but the force generated by the patient was not different between spontaneous and mandatory cycles. This lack of adaptation to spontaneous and mandatory breaths precluded effective unloading of the respiratory muscles. ${ }^{12}$ Leung et al found that, during SIMV, missed triggers were common immediately after mandatory breaths as a result of the larger $\mathrm{V}_{\mathrm{T}}$ and longer inspiratory time. By reducing the mandatory breath rate, missed triggers were reduced in part as respiratory drive increased. Both of these studies conclude that the use of SIMV in COPD patients is ineffective in unloading the respiratory muscles. ${ }^{44}$

Jaber et al compared PSV to volume support ventilation during a period of increased ventilatory drive created by adding dead space to the breathing circuit. They found that during volume support ventilation, as patient demand increased, ventilator output decreased, resulting in greater increases in the work of breathing, compared to PSV. ${ }^{45}$ The increase in respiratory effort increases delivered $\mathrm{V}_{\mathrm{T}}$.
The ventilator algorithm responds by reducing the delivered pressure, shifting work to the patient. This effect occurs with other adaptive pressure modes as well, but seems to be less severe with $\dot{\mathrm{V}}_{\mathrm{E}}$ controllers. ${ }^{46}$

\section{Premature and Prolonged Cycling}

Premature cycling or short cycling occurs with poor matching of neural and ventilator inspiratory times. When the patient's neural inspiratory time exceeds the ventilator inspiratory time, the asynchrony is known as premature cycling. When the ventilator inspiratory time exceeds the patients neural inspiratory time, the asynchrony is known as prolonged or delayed cycling. Delayed cycling is common during PSV in patients with obstructive lung disease, leading to missed triggers. ${ }^{6,24,37}$ The flow termination criteria of the ventilator also has an important impact on the development and resolution of prolonged cycling. ${ }^{47-52}$ Premature cycling can occur when high a flow termination criterion is utilized in patients with restrictive lung mechanics. ${ }^{53-55}$ In these instances, missed triggers are reduced, but the work of breathing and incidence of double triggering increases.

\section{Identifying Asynchrony}

From a clinical standpoint, evaluation of airway pressure, flow, and volume signals on the ventilator display is the most frequently used method for detecting asynchrony. ${ }^{56-58}$ However, monitoring esophageal pressure, electrical activity of the diaphragm, and diaphragmatic electromyogram can supply additional information, but are not routine or practical.6,59,60 The more invasive techniques are less likely to be affected by artifacts and are more sensitive at detecting asynchrony. However, the everyday care of patients in the ICU, for the moment, relies on the airway graphics. ${ }^{61}$

Epstein has detailed a number of issues that impact the detection and reported incidence of asynchrony. ${ }^{6}$ These include the timing, duration, and number of observations. Short periods of observation are likely to under-report asynchrony. Similarly, observation of patients during periods of heavy sedation are unlikely to observe substantial asynchrony. Timing is important as well; the degree of asynchrony is likely very different on day 1 than day 7 or 14 . Several observational periods over the course of a single day might detect a greater incidence of asynchrony, compared to a daily measurement and at a specified time. The mode of mechanical ventilation and lung mechanics of the study population also impact the reported incidence of asynchrony. ${ }^{62}$ Neuromuscular weakness, heavy sedation, and COPD are more likely to result in missed triggers, although in the latter diagnosis the mechanism is different. Elevated $V_{T}$ and $\dot{V}_{E}$ settings are associated with greater 
asynchrony, despite the greater level of machine support. Patient-ventilator interaction is complex, and the number of factors influencing synchrony requires a careful bedside approach and the appropriate application of ventilator technology to remedy the problem.

\section{Automated Detection of Asynchrony}

To date, detection of asynchrony has required well trained clinicians at the bedside. More recently, several investigators have explored the use of machine learning and pattern recognition to automatically detect asynchrony. ${ }^{63-67}$ In most instances these systems specifically address the issue of missed triggers. Chen et al used measurements of flow and pressure deflections to detect missed triggers in 14 mechanically ventilated patients. They demonstrated a sensitivity and specificity of $>90 \%$ for detecting missed triggers. ${ }^{63}$ Mulqueeney and others have shown that pattern recognition software can detect missed triggers during the expiratory phase with an overall accuracy of near $95 \% .64,65$

More recently, Blanch and colleagues have evaluated the Better Care system for detection of missed triggers during invasive ventilation. ${ }^{66}$ The Better Care software calculates a theoretical mono-exponential expiratory flow curve and compares it to the actual expiratory flow curve by evaluating the percentage deviation. The system uses a series of curves with no evidence of missed triggers and averages these to create an ideal curve. The actual expiratory flow curves are then compared to the ideal. The authors report that the system is able to detect the presence of secretions in the patient/ventilator circuit and eliminate this artifact. They studied 8 patients, collecting over 2 million breaths, of which a random sampling of 1,024 breaths were analyzed. The authors classified the breaths as including a missed trigger or not, and compared the automatic system to the analysis of experts and data from electrical-activity-of-the-diaphragm signals. As in other studies, the authors demonstrated a sensitivity and specificity of $>90 \%$.

Cuvelier and colleagues studied a system to automatically detect missed triggers during NIV. ${ }^{67}$ They evaluated 14 cystic fibrosis patients receiving nocturnal NIV. These authors evaluated both pressure and flow tracings while comparing the algorithm to esophageal pressure measurements. They displayed the flow tracings as a 2-dimensional graph in space with a time delay. The presence of missed triggers resulted in 2 distinct graphs with similar shapes but significantly different magnitudes. The difference in the size of the tracings demonstrates the presence of missed triggers. The algorithm correctly identified $100 \%$ of triggered cycles and 53/56 (94.6\%) of missed triggers. They noted that when missed triggers were identified, the $\dot{\mathrm{V}}_{\mathrm{E}}$ was significantly reduced.
Each of these systems appears to lend itself to implementation in a mechanical ventilation system. However, there are limitations. One issue is the presentation of the information to the clinician. Would every missed trigger be reported? Would only those subjects with an asynchrony index $>10 \%$ have a warning or alarm displayed on the ventilator? What effects would variable leaks, condensate in the circuit, and secretions in the artificial airway have on the accuracy of these systems? Would the ventilator display the number of missed triggers as a function of the total breathing frequency? If the system detected missed triggers, could the detection lead to triggering algorithms that would eliminate the missed triggers? In the latter instance, perfect patient-ventilator interaction (one ventilator breath for each patient effort) could lead to elevated $\dot{V}_{\mathrm{E}}$ and, in the case of obstructive lung disease, worsening of intrinsic PEEP.

Cardiac systems available in ICUs and physicians' offices have had pattern recognition and automated diagnoses on electrocardiographic rhythms for many years. Respiratory monitoring has been slow to catch up. These systems require further investigation to determine the best method for detection and the best methods for conveying that information to the clinician in a manner that positively impacts patient comfort.

\section{Incidence of Asynchrony and Outcomes}

The incidence of asynchrony has been reported by a number of investigators. ${ }^{19-23,62}$ With the background by Epstein that the reported incidence has a number of pitfalls, there has been a growing body of literature evaluating this topic. ${ }^{6}$ Importantly, invasive and noninvasive ventilation have different types of asynchrony and different reported rates; these are discussed separately below.

\section{Invasive Ventilation}

The reported incidence of asynchrony during invasive ventilation is limited in that several studies report only the incidence of missed triggers, while others include other types of asynchrony as well. Table 2 details the results of these studies. There is a wide range reported for the asynchrony rate $(10-85 \%)$. One study evaluated patients in a regional weaning facility ${ }^{20}$ while the others are acute care hospital studies. ${ }^{19,21-23,62}$ An evaluation of these 6 trials suggests that during invasive ventilation, missed triggers are the most common asynchrony. In the study by Thille et al, in a medical ICU with a number of COPD patients, missed triggers accounted for $85 \%$ of all reported asynchronies. ${ }^{21}$ Robinson et al evaluated a group of injured patients and found few instances of missed triggers, despite the fact that a quarter of the patients had a diagnosis 
Table 2. Comparison of Rates of Asynchrony During Invasive Ventilation

\begin{tabular}{|c|c|c|c|c|c|c|}
\hline $\begin{array}{l}\text { First } \\
\text { Author }\end{array}$ & $\begin{array}{l}\text { No. of Patients/ } \\
\text { No. With } \\
\text { Asynchrony } \\
(\%)\end{array}$ & Setting & $\begin{array}{l}\text { Types of } \\
\text { Asynchrony } \\
\text { Reported }\end{array}$ & $\begin{array}{l}\text { Asynchrony } \\
\text { Index } \\
(\%)\end{array}$ & $\begin{array}{l}\text { Factors Associated } \\
\text { With Asynchrony }\end{array}$ & Outcomes \\
\hline Fabry ${ }^{19}$ & $11 / 9(81)$ & Medical ICU & Missed triggers & 18 & Not reported & Not reported \\
\hline $\mathrm{Chao}^{20}$ & $174 / 19(10.9)$ & $\begin{array}{l}\text { Regional weaning } \\
\text { center }\end{array}$ & Missed triggers & 54 & $\begin{array}{l}\text { COPD } \\
\text { Hypercapnia } \\
\text { Reduced maximum inspiratory } \\
\quad \text { pressure }\end{array}$ & $\begin{array}{l}\text { Weaning success: asynchrony } 16 \% \text {, } \\
\text { no asynchrony } 57 \% \\
\text { Ventilation duration: asynchrony } \\
72 \mathrm{~d} \text {, no asynchrony } 33 \mathrm{~d}\end{array}$ \\
\hline Thille $^{21}$ & $62 / 15(24)$ & Mixed ICU & $\begin{array}{l}\text { Missed triggers: } \\
85 \% \\
\text { Double triggering: } \\
13 \% \\
\text { Auto-triggering, } \\
\text { short cycle, } \\
\text { prolonged cycle: } \\
<1 \%\end{array}$ & 26 & $\begin{array}{l}\mathrm{COPD} \\
\text { Elevated } \mathrm{HCO}_{3}^{-} \text {and } \mathrm{pH} \\
\text { Larger tidal volume } \\
\text { Higher peak inspiratory } \\
\quad \text { pressure or pressure support }\end{array}$ & $\begin{array}{l}\text { Ventilation duration: asynchrony } \\
23 \mathrm{~d} \text {, no asynchrony } 13 \mathrm{~d} \\
\text { Incidence of tracheostomy: } 33 \% \text { vs } \\
4 \% \\
\text { Mortality: } 47 \% \text { vs } 32 \% \text {, difference } \\
\text { not significant }\end{array}$ \\
\hline de Witt ${ }^{22}$ & 20/17 (85) & Medical ICU & Missed triggers & 9 & $\begin{array}{l}\text { Deeper sedation } \\
\text { Lower Richmond Agitation- } \\
\text { Sedation Scale (RASS) } \\
\text { score } \\
\text { Coma }\end{array}$ & Not reported \\
\hline de Witt ${ }^{23}$ & $60 / 16(26.6)$ & Medical ICU & Missed triggers & 16 & $\begin{array}{l}\text { Pressure triggering } \\
\text { Higher intrinsic breathing } \\
\text { frequency }\end{array}$ & $\begin{array}{l}\text { Asynchrony associated with longer } \\
\text { duration of ventilation, shorter } \\
\text { ventilator-free survival, longer } \\
\text { ICU and hospital stay }\end{array}$ \\
\hline Robinson $^{62}$ & $35 / 9(25.7)$ & $\begin{array}{l}\text { Surgical/trauma } \\
\text { ICU }\end{array}$ & $\begin{array}{l}\text { Missed triggers } \\
\text { Double triggering } \\
\text { Auto-triggering } \\
\text { Short cycle } \\
\text { Prolonged cycle } \\
\text { Breath stacking }\end{array}$ & 16 & $\begin{array}{l}\text { Higher set breathing frequency } \\
\text { in synchronized intermittent } \\
\text { mandatory ventilation } \\
\text { (SIMV) }(>10 \text { breaths/min) } \\
\text { Lower spontaneous breathing } \\
\text { frequency }\end{array}$ & $\begin{array}{l}\text { No difference in duration of } \\
\text { ventilation, ICU stay, or } \\
\text { mortality }\end{array}$ \\
\hline
\end{tabular}

of COPD. However, an exacerbation of COPD is not what brought these patients to the ICU. Pain and anxiety following trauma and surgery likely impact these patients, compared to the COPD patients who requires intubation following an exacerbation.

Robinson et al found during the use of adaptive pressure ventilation (AutoFlow, Dräger, Telford, Pennsylvania) in the SIMV mode that "breath stacking" was a common asynchrony. While traditional volume control modes attempt to prevent breath stacking during SIMV, this algorithm appears to allow a pressure support breath to begin and then be followed by a mandatory breath, prior to exhalation (Fig. 5). Because the breaths are pressure limited, this stacking may not have the consequences seen with a volume breath. However, Figure 1 clearly demonstrates a stair step breath delivery with an inspiratory time longer than the set inspiratory time, and an increased $\mathrm{V}_{\mathrm{T}}$. The clinical implications of this finding are unclear. These authors also found that asynchrony was more common when set ventilator frequency was $>10$ breaths/min in the SIMV mode.

\section{Asynchrony and Outcome}

The presence and severity of asynchrony is associated with prolonged mechanical ventilation, longer ICU stay, and mortality. However, we do not know if asynchrony simply serves as an indicator of severity of illness or if asynchrony results in prolonged duration of ventilation. Manufacturers find it attractive to say that if asynchrony can be improved by new modes, then outcomes can be improved. However, synchrony has no therapeutic effects, and improving synchrony does not guarantee better outcomes. Chao et al demonstrated in 174 chronically ventilator dependent patients that those with ineffective triggered breaths required a longer duration of mechanical ventilation (70 d vs $33 \mathrm{~d}$ ) and a lower rate of eventual liberation (16\% vs 57\%). ${ }^{20}$ Thille et al reaffirmed an association of prolonged mechanical ventilation with an asynchrony index $>10 \%$ (median duration $25 \mathrm{~d}$ vs $9 \mathrm{~d}$ ), and also described a higher rate of tracheostomy in the asynchrony group (33\% vs 4\%). ${ }^{21}$ Both of these important works were performed in older critically ill medical pop- 

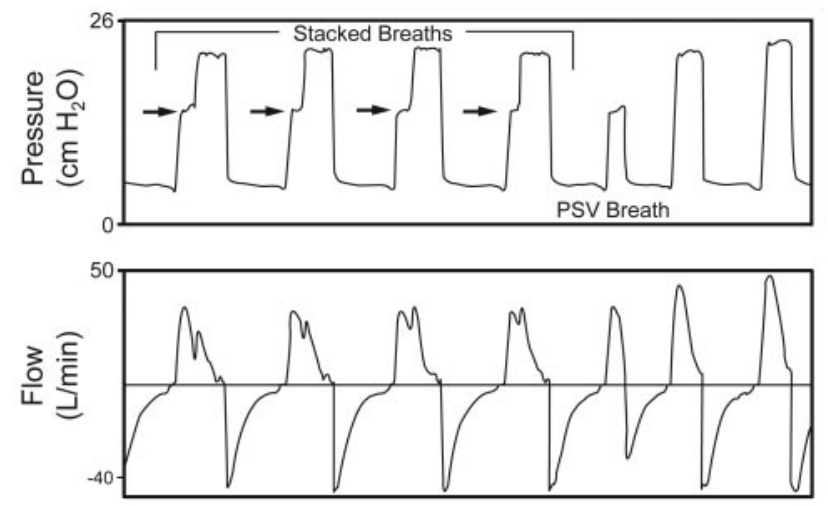

Fig. 5. Breath stacking during synchronized intermittent mandatory ventilation (SIMV plus pressure support) with adaptive pressure breaths. The arrows demonstrate the pressure support setting. The first 4 breaths have mandatory breaths stacked on top of spontaneous breaths. PSV = pressure support ventilation.

ulations (69-75 y old), with a quarter having the diagnosis of COPD. The study by de Wit and colleagues included a total of 60 patients and found that an asynchrony rate of $>10 \%$ was associated with a longer duration of ventilation, reduced ventilator-free survival, and longer ICU and hospital stay. ${ }^{23}$ The report by Robinson et al in trauma patients does not demonstrate any difference in duration of ventilation, ICU stay, or mortality in those patients with an asynchrony index $>10 \% .{ }^{62}$ These findings likely represent the difference in indications for mechanical ventilation and type of respiratory dysfunction.

\section{Asynchrony in NIV}

The major difference in patient-ventilator synchrony during NIV is the presence of leaks (intentional and unintentional) in the circuit and mask, complicating ventilator breath delivery. Vignaux et al evaluated 60 patients with acute respiratory failure during NIV to determine the prevalence of patient-ventilator asynchrony. ${ }^{68}$ The authors used 30 min recordings of airway pressure, flow, and surface diaphragmatic electromyography to detect asynchrony. They defined asynchrony events as ineffective triggering, double triggering, auto-triggering, premature cycling, and delayed cycling. An asynchrony index $>10 \%$ was considered severe asynchrony, based on previous studies. ${ }^{21}$ The investigators also determined patient comfort using a visual analog scale.

They reported the presence of auto-triggering in 8 patients (13\%), double triggering in 9 patients (15\%), missed triggers in 8 patients $(13 \%)$, premature cycling in 7 patients (12\%), and late cycling in 14 patients (23\%). One type of asynchrony was identified in 18 patients, 10 patients had 2 types, and 4 had 3 types. The asynchrony index was $>10 \%$ in 26 patients (43\%). Factors predicting an asynchrony index $>10$ were the level of pressure support and the magnitude of leak (the greater the leak, the greater the asynchrony index).

Carteaux and colleagues evaluated NIV in 15 patients during 3 periods of observation. ${ }^{34}$ This study included a sophisticated bench study of ventilators used for NIV, detailing the impact of leaks on asynchrony. They found that ICU ventilators commonly demonstrated auto-triggering, which was improved by the activation of the NIV mode of the device to enhance leak compensation. However, they found that the ventilators designed for NIV meant to work with a leak in the system had the lowest incidence of auto-triggering. In the patient study the asynchrony index was significantly lower with a dedicated NIV ventilator, compared to an ICU ventilator, with or without the NIV algorithm activated. The asynchrony index was $0.5 \%(0.4-$ $1.2 \%)$ for dedicated NIV devices, $3.7 \%(1.4-10.3 \%)$ for ICU ventilators, and $2.0 \%$ (1.5-6.6\%) for ICU ventilators with the NIV algorithm engaged. The major difference was a decrease in the number of auto-triggers.

In a comparison of ICU ventilators with and without NIV algorithms engaged, Vignaux et al studied 65 patients during NIV. They reported asynchrony rates without and with the NIV algorithm as: auto-triggering in 14 (22\%) and $10(15 \%)$ patients, missed triggers in $15(23 \%)$ and 5 $(8 \%)(P=.004)$, late cycling in $11(17 \%)$ and $5(8 \%)$ $(P=.003)$, premature cycling in $22(34 \%)$ and $21(32 \%)$, and double triggering in $3(5 \%)$ and $6(9 \%) .{ }^{38}$ The mean number of asynchronies created by leaks was significantly reduced by the NIV algorithm. They found a significant correlation between asynchrony and the magnitude of leaks when the NIV algorithm was not activated $(P=.03)$. Interestingly, the total asynchrony index did not change, as on several ventilators the NIV algorithm appears to increase the rate of premature cycling.

The study by Carteaux et al is compelling in that the bench study supports the clinical findings. ${ }^{34}$ However, compared to the study by Vignaux et al, the rate of asynchrony was very low, regardless of the type of ventilator. ${ }^{68}$ So, while the difference in the actual incidence of asynchrony was 6-fold or more, the asynchrony index remained below $10 \%$ in all cases. It cannot be argued, however, that the leak compensation of dedicated NIV ventilators has been shown to be superior to ICU ventilators in this and a number of other studies..$^{38,68-72}$ ICU ventilators perform better when the NIV algorithm is implemented, and clearly some ICU ventilators perform better than others.

The interface used with NIV impacts patient-ventilator interaction and patient comfort. ${ }^{10}$ Additionally, the type of humidification device and level of humidity can impact synchrony with respect to rebreathing and patient comfort. ${ }^{10,73-76}$ These factors have been described in detail by Hess. ${ }^{10}$ 

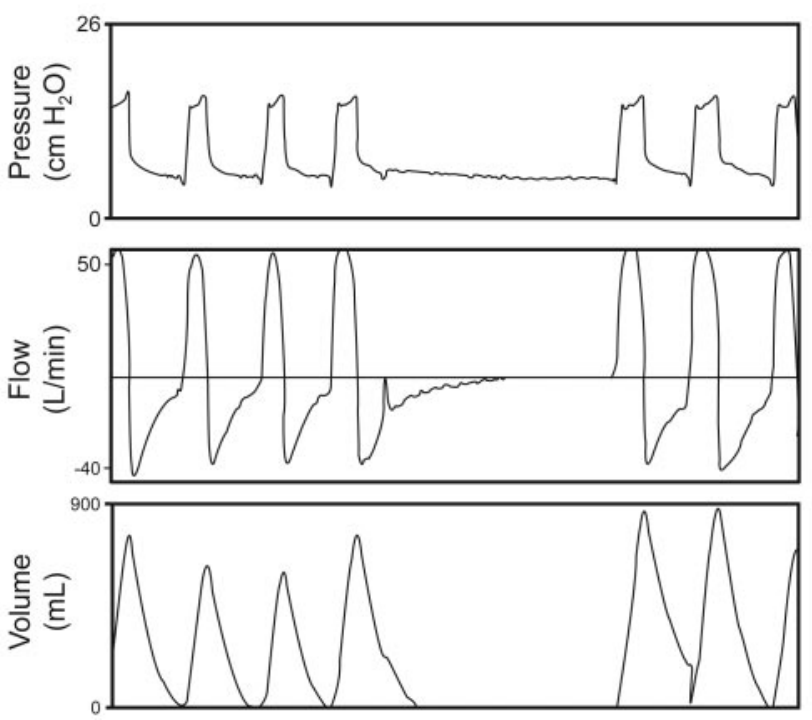

Fig. 6. Excessive level of pressure support resulting in large tidal volumes $(\approx 700 \mathrm{~mL})$, resulting in periodic breathing in an ICU patient. This pattern is associated with sleep arousals.

\section{Asynchrony and Outcome in NIV}

Vignaux et al found that the comfort score was higher in patients with an asynchrony index $<10 \%$ during NIV, but found no association between intubation rate, stay in ICU, or mortality and an asynchrony index $>10 \% .{ }^{68}$ The work by Carteaux and others did not attempt to evaluate outcomes. The study by Vignaux and colleagues comparing ICU ventilators with and without NIV algorithms showed no difference in the total asynchrony index incidence, but no other outcomes were assessed.

\section{Asynchrony and Sleep}

Parthasarathy and colleagues demonstrated significant alterations in sleep patterns associated with the mode of ventilatory support. ${ }^{77}$ These early findings have been confirmed by a number of other authors. ${ }^{78-84}$ The data suggest that in patient triggered modes of ventilation, excessive support (too high pressure level in PSV or too high a gain in proportional assist ventilation) can result in the patient's $\mathrm{P}_{\mathrm{aCO}}$ falling below the apneic threshold. This is followed by a period of apnea during which $\mathrm{P}_{\mathrm{aCO}_{2}}$ increases and the drive to breathe causes arousal from sleep.(Fig. 6) More recently, Alexopoulou and colleagues suggested that while proportional assist ventilation improves synchrony during sleep in ICU patients, there was no difference in the quality of sleep. ${ }^{84}$ Delisle found that neurally adjusted ventilatory assist improved sleep quality, compared to PSV. They reported greater missed triggers during PSV, along with more sleep arousals. This was a crossover trial with short $(4 \mathrm{~h})$ periods of observation. ${ }^{81}$
Córdoba-Izquierdo et al evaluated sleep during NIV with dedicated NIV ventilators and ICU ventilators in 24 patients with hypercapnic respiratory failure. ${ }^{82}$ They reported that sleep architecture was similar between groups, including sleep fragmentation (number of arousals and awakenings per hour). However, the dedicated noninvasive ventilators demonstrated a higher patient-ventilator asynchrony-related sleep fragmentation (28\% [17-44\%] vs $14 \%[7.0-22 \%], P=.02)$, while ICU ventilators created a higher noise-related sleep fragmentation. Missed triggers were more frequent with the dedicated NIV ventilators. They reported more sleep time and better sleep quality during NIV, compared to spontaneous breathing periods $(P<.05)$. These findings are in conflict with previous data regarding NIV dedicated ventilators from this same group of investigators. However, it is important to note that, while in this instance there was no difference is sleep quality with the 2 different types of ventilators, sleep during NIV was still superior to sleep during unassisted breathing.

\section{Unresolved Issues}

While our understanding of patient-ventilator interaction continues to improve, there remain issues that are unresolved and require further investigation.

\section{Asynchrony and Respiratory Muscle Dysfunction}

As early as 1985, Marini et al suggested that insufficient unloading of the respiratory pump during mechanical ventilation could result in respiratory muscle fatigue and injury. ${ }^{11}$ In the intervening years a number of animal studies suggest that ventilator-induced diaphragmatic dysfunction (VIDD) can occur. ${ }^{85-88}$ These studies often include the use of continuous mandatory ventilation, which is rarely used in humans, with the exception of those cases requiring paralysis. The importance of VIDD in humans is becoming better understood and is considered here.

During normal breathing the inspiratory muscles, primarily the diaphragm, shorten during contraction. During expiration the diaphragm lengthens as lung volume passively falls to functional residual capacity. As we have seen, in obstructive lung disease, missed triggers occur primarily during expiration. Contraction of the diaphragm during the expiratory phase, as occurs with a missed trigger, can result in muscle contraction during lengthening. In skeletal limb muscles this type of contraction, known as eccentric or pliometric contraction, leads to muscle fiber injury and reduced strength.

Studies in humans have demonstrated the presence of VIDD over short periods of ventilatory support. ${ }^{89-91}$ The landmark work by Levine ${ }^{90,91}$ in brain-dead patients has shown conclusively that VIDD occurs following 18 
69 hours of complete diaphragmatic inactivity coupled with mechanical ventilation. Biopsies of the diaphragm demonstrate marked atrophy of myofibers. These findings are consistent with increased diaphragmatic proteolysis during inactivity. Hermans ${ }^{92}$ and others ${ }^{93,94}$ have also demonstrated VIDD and progressive diaphragmatic muscle weakness during short-term ventilatory support.

The unresolved issues surrounding asynchrony and VIDD are related to confounding factors and the difficulty in determining the amount of work the respiratory muscles should do during respiratory failure. Even the human work of Levine and others is complicated by the presence of sedation and analgesia. Sepsis is also an important confounding factor that can lead to muscle atrophy in the absence of mechanical ventilation. The study by Papazian et al demonstrating short-term paralysis results in improved outcomes in ARDS further complicates the issue. ${ }^{95}$ These authors have suggested that early short-term paralysis facilitates lung-protective mechanical ventilation by improving patient-ventilator synchrony and limiting both asynchrony-related de-recruitment and regional overdistention. While this strategy allows an assessment of the patient's status and does potentially reverse these 2 components of ventilator-induced lung injury, it is unclear how even shortterm paralysis is advantageous for diaphragmatic muscle strength.

\section{Asynchrony and Dyspnea}

Dyspnea is a subjective experience of breathing discomfort that consists of qualitatively distinct sensations that vary in intensity. Dyspnea is often thought of as a sensation similar to pain, which avoids an objective definition. Other attempts at defining dyspnea include "difficulty in breathing," "disordered or inadequate breathing," "uncomfortable awareness of breathing," and as the experience of "breathlessness."96,97 Dyspnea is a common manifestation of respiratory and cardiac disease, resulting from an increase in respiratory drive or effort required to overcome an imposed load, in the proportion of respiratory muscle force required for breathing, and in $\dot{\mathrm{V}}_{\mathrm{E}}$ requirements. ${ }^{96}$ The sensation of dyspnea and the underlying physiology are complex and include interaction of chemoreceptors, peripheral sensory receptors, the cerebral cortex, and "psychophysics." Dyspnea commonly occurs in conscious patients, and the patient's experience is an important component of the diagnosis and treatment. ${ }^{96}$

Few studies have evaluated the interaction between dyspnea and synchrony. In an early trial, Leung et al compared continuous mandatory ventilation to SIMV and SIMV plus pressure support and PSV alone in 11 hemodynamically stable patients. They evaluated pressure-time product and respiratory drive, and measured dyspnea using the Borg scale. ${ }^{44}$ Patients were placed on an IMV rate equiv- alent to the rate in continuous mandatory ventilation. The IMV rate was then decreased from $100 \%$ of that value to $0 \%$. Pressure support of $10 \mathrm{~cm} \mathrm{H}_{2} \mathrm{O}$ was added to IMV or provided at a level that delivered a $\mathrm{V}_{\mathrm{T}}$ of $10 \mathrm{~mL} / \mathrm{kg}$. Pressure support was then likewise decreased in $20 \%$ increments, and finally spontaneous breathing was evaluated. They found that increases in the level of ventilator assistance produced progressive decreases in inspiratory muscle work, but also resulted in more missed triggers. Missed triggers were more common at higher levels of assistance, presumably due to a reduction in ventilatory drive. Dyspnea was reduced in spite of the increased missed triggers, and PSV was superior to IMV at low levels of assistance.

Knebel et al compared Borg scores in patients during weaning, using both IMV and PSV. ${ }^{98}$ In 21 patients requiring mechanical ventilation for $>3$ days, breathing comfort was measured during sequential reductions in the level of assistance, using both SIMV and PSV weaning. Breathing comfort was defined by subjective ratings of dyspnea and anxiety. Patients reported substantial levels of dyspnea and anxiety prior to initiation of weaning attempts, despite having rested for at least 6 hours prior to study start. Dyspnea and anxiety were not significantly different between the 2 methods. The authors concluded that dyspnea and anxiety were higher than expected on "full" ventilatory support, and that comfort may not differ between PSV and SIMV during active weaning of ventilator support. ${ }^{98}$

More recently, Schmidt and co-workers have reevaluated the impact of dyspnea during mechanical ventilation, and particularly the role of asynchrony. ${ }^{99}$ The authors studied 96 patients requiring mechanical ventilation for $>24$ hours. Patients were asked if they had dyspnea, using a yes or no response, and then were allowed to qualify the answer as due to air hunger or respiratory effort. The Borg scale was used along with visual analog scales for pain and anxiety. Forty-five patients (47\%) reported dyspnea, with respiratory effort being identified in 7 cases, air hunger in 15 cases, both in 16 cases, and neither in 7 cases. There was no difference between dyspneic and nondyspneic patients in terms of age, Simplified Acute Physiology Score II, indication for mechanical ventilation, breathing frequency, clinical examination, chest radiograph, or blood gases. Dyspnea was significantly associated with anxiety (odds ratio $8.84,95 \% \mathrm{CI}, 3.26-24.0$ ), volume control continuous mandatory ventilation (odds ratio $4.77,95 \%$ CI 1.60 4.3), and heart rate (odds ratio 1.33 per 10 beats/min, 95\% CI 1.02-1.75). An important goal of the study was to determine the role of adjustments in mechanical ventilator settings as a method to reduce dyspnea. In patients receiving continuous mandatory ventilation, increases in $\mathrm{V}_{\mathrm{T}}$, inspiratory flow, and PEEP were made systematically, with reevaluation of dyspnea following each change. Patients 
receiving PSV had increases in the pressure support level, followed by increases in the trigger sensitivity.

The authors arbitrarily determined that ventilator settings were involved in the pathogenesis of dyspnea when the post-intervention visual analog scale rating was lower than the pre-intervention level by at least $1 \mathrm{~cm}$. Patients were placed into 2 groups: those who had a reduction in dyspnea following ventilator manipulation, and those who did not. Adjusting ventilator settings improved dyspnea in only $35 \%$ of patients.

There was a significant difference in the rate of successful extubation within 3 days of evaluation between patients who had a reduction in dyspnea, compared to those who did not. Extubation was significantly less frequent in patients whose dyspnea failed to recede after adjusting ventilator settings (5 [17\%] vs $27[40 \%], P<.03$ ). ICU stay was also longer for the group whose dyspnea could not be ameliorated by ventilator manipulations. The authors concluded that dyspnea was frequent, intense, and strongly associated with anxiety in mechanically ventilated patients. The inability to alleviate dyspnea with ventilator manipulations predicted longer duration of ICU stay and longer time until successful extubation.

These findings are important to the discussion of patient-ventilator synchrony. While manipulating ventilator settings reduced dyspnea in a third of patients, more importantly, two thirds of patients were unaffected by ventilator alterations. In these cases a combination of sedation and analgesia may be required. However, excess sedation should be avoided, as this can also lead to prolonged ventilatory support.

Finally, there is evidence that the patients' subjective impressions of their own ability to breathe spontaneously correlated with successful extubation, which suggests that, when possible, we should include our patients in the discussion, and, when possible, the decision. ${ }^{100}$

\section{Summary}

Patient-ventilator synchrony is a complex issue that includes patient factors, ventilator type, interface, mode, ventilator settings, and the patient's sensation of dyspnea. Sedation and analgesia also play an important role. VIDD appears to be following the path of ventilator-induced lung injury, and our future ventilator strategies will have to consider this issue. The role of paralysis is unclear, but it may be both helpful and harmful. Ventilators have a host of methods for improving synchrony, and these should be studied in light of the findings that only one third of patients can have their dyspnea ameliorated by changes in ventilator output. Additionally, the impact of patient-ventilator interaction and synchrony on outcomes needs to be evaluated to determine if asynchrony simply predicts severity of illness and prolonged ventilation, or causes it.
Finally, NIV use continues to increase, and clinicians should understand the causes of asynchrony during NIV as well as potential remedies.

\section{REFERENCES}

1. Wunsch H, Linde-Zwirble WT, Angus DC, Hartman ME, Milbrandt EB, Kahn JM. The epidemiology of mechanical ventilation use in the United States. Crit Care Med 2010;38(12):1947-1953.

2. Tobin MJ, Fahey PJ. Management of the patient who is "fighting the ventilator." In: Tobin MJ, Fahey PJ, editors. Principles and practice of mechanical ventilation. New York: McGraw Hill; 1994.

3. Kallet RH. Patient-ventilator interaction during acute lung injury, and the role of spontaneous breathing. Part 2: airway pressure release ventilation. Respir Care 2011;56(2):190-203; discussion 203206.

4. Kallet RH. Patient-ventilator interaction during acute lung injury, and the role of spontaneous breathing. Part 1: respiratory muscle function during critical illness. Respir Care 2011;56(2):181-189.

5. de Wit M. Monitoring of patient-ventilator interaction at the bedside. Respir Care 2011;56(1):61-72.

6. Gentile MA. Cycling of the mechanical ventilator breath. Respir Care 2011;56(1):52-60

7. Sassoon CSH. Triggering of the ventilator in patient-ventilator interactions. Respir Care 2011;56(1):39-51.

8. Epstein SK. How often does patient-ventilator asynchrony occur and what are the consequences? Respir Care 2011;56(1):25-38.

9. Branson RD. Patient-ventilator interaction: the last 40 years. Respir Care 2011;56(1):15-24

10. Hess DR. Patient-ventilator interaction during noninvasive ventilation. Respir Care 2011;56(2):153-165; discussion 165-167.

11. Marini JJ, Capps JS, Culver BH. The inspiratory work of breathing during assisted mechanical ventilation. Chest 1985;87(5): 612-618.

12. Marini JJ, Smith TC, Lamb VJ. External work output and force generation during synchronized intermittent mechanical ventilation: effect of machine assistance on breathing effort. Am Rev Respir Dis 1988;138(5):1169-1179.

13. Marini JJ, Rodriguez RM, Lamb V. Bedside estimation of the inspiratory work of breathing during mechanical ventilation. Chest 1986;89(1):56-63.

14. MacIntyre NR, McConnell R, Cheng KC, Sane A. Patient-ventilator flow dyssynchrony: flow-limited versus pressure-limited breaths. Crit Care Med 1997;25(10):1671-1677.

15. Tobin MJ, Jubran A, Laghi F. Patient-ventilator interaction. Am J Respir Crit Care Med 2001;163(5):1059-1063.

16. Laghi F, Karamchandani K, Tobin MJ. Influence of ventilator settings in determining respiratory frequency during mechanical ventilation. Am J Respir Crit Care Med 1999;160(5):1766-1770.

17. Gurevitch MJ, Gelmont D. Importance of trigger sensitivity to ventilator response delay in advanced chronic obstructive pulmonary disease with respiratory failure. Crit Care Med 1989; 17(4):354-359.

18. Ashutosh K, Gilbert R, Auchincloss JH Jr, Peppi D. Asynchronous breathing movements in patients with chronic obstructive pulmonary disease. Chest 1975;67(5):553-557.

19. Fabry B, Guttmann J, Eberhard L, Bauer T, Haberthur C, Wolff G. An analysis of desynchronization between the spontaneously breathing patient and ventilator during inspiratory pressure support. Chest 1995;107(5):1387-1394.

20. Chao DC, Scheinhorn DJ, Stearn-Hassenpflug M. Patient-ventilator trigger asynchrony in prolonged mechanical ventilation. Chest 1997; 112(6):1592-1599. 


\section{ASYNCHRONY AND DYSPNEA}

21. Thille AW, Rodriguez P, Cabello B, Lellouche F, Brochard L. Patient-ventilator asynchrony during assisted mechanical ventilation. Intensive Care Med 2006;32(10):1515-1522.

22. de Wit M, Pedram S, Best AM, Epstein SK. Observational study of patient-ventilator asynchrony and relationship to sedation level. J Crit Care 2009;24(1):74-80

23. de Wit M, Miller KB, Green DA, Ostman HE, Gennings C, Epstein SK. Ineffective triggering predicts increased duration of mechanical ventilation. Crit Care Med 2009;37(10):2740-2745.

24. Hill LL, Pearl RG. Flow triggering, pressure triggering, and autotriggering during mechanical ventilation. Crit Care Med 2000;28(2): 579-581.

25. Imanaka H, Takeuchi M, Tachibana K, Nishimura M. Exhaled tidal volume overestimation in mechanically ventilated patients with large cardiogenic oscillation. Crit Care Med 2004;32(7):1546-1549.

26. Arbour R. Cardiogenic oscillation and ventilator autotriggering in brain-dead patients: a case series. Am J Crit Care 2009;18(5):496, 488-495.

27. Arbour RB. Confounding factors in brain death: cardiogenic ventilator autotriggering and implications for organ transplantation. Intensive Crit Care Nurs 2012;28(6):321-328.

28. Imanaka H, Nishimura M, Takeuchi M, Kimball WR, Yahagi N, Kumon K. Autotriggering caused by cardiogenic oscillation during flow-triggered mechanical ventilation. Crit Care Med 2000;28(2): 402-407.

29. Sheikh E, Maguire DP, Gratch D. Autotriggering during pressure support ventilation due to cardiogenic oscillations. Anesth Analg 2009;109(2):470-472.

30. Dodd-Sullivan R, Quirin J, Newhart J. Ventilator autotriggering: a caution in brain death diagnosis. Prog Transplant 2011;21(2):152155 .

31. Willatts SM, Drummond G. Brainstem death and ventilator trigger settings. Anaesthesia 2000;55(7):676-677.

32. McGee WT, Mailloux P. Ventilator autocycling and delayed recognition of brain death. Neurocrit Care 2011;14(2):267-271.

33. France TE, Garnett AR, Grooms D. Inadvertent triggering of the ventilator caused by surgically placed pacer wires. Respir Care 2012;57(8):1334-1336.

34. Carteaux G, Lyazidi A, Cordoba-Izquierdo A, Vignaux L, Jolliet P, Thille AW, et al. Patient-ventilator asynchrony during noninvasive ventilation: a bench and clinical study. Chest 2012;142(2):367-376.

35 . Hess DR, Branson RD. Know your ventilator to beat the leak. Chest 2012;142(2):274-275.

36. Prinianakis G, Kondili E, Georgopoulos D. Effects of the flow waveform method of triggering and cycling on patient-ventilator interaction during pressure support. Intensive Care Med 2003; 29(11):1950-1959.

37. Kondili E, Prinianakis G, Georgopoulos D. Patient-ventilator interaction. Br J Anaesth 2003;91(1):106-119.

38. Vignaux L, Tassaux D, Carteaux G, Roeseler J, Piquilloud L, Brochard L, Jolliet P. Performance of noninvasive ventilation algorithms on ICU ventilators during pressure support: a clinical study. Intensive Care Med 2010;36(12):2053-2059.

39. Akoumianaki E, Lyazidi A, Rey N, Matamis D, Perez-Martinez N, Giraud R, et al. Mechanical ventilation-induced reverse triggered breaths: a frequently unrecognized form of neuro-mechanical coupling. Chest 2012 [Epub ahead of print] doi: 10.1378/chest.121817.

40. Baconnier PF, Benchetrit G, Pachot P, Demongeot J. Entrainment of the respiratory rhythm: a new approach. J Theor Biol 1993; 164(2):149-162.

41. Simon PM, Zurob AS, Wies WM, Leiter JC, Hubmayr RD. Entrainment of respiration in humans by periodic lung inflations. Ef- fect of state and $\mathrm{CO}_{2}$. Am J Respir Crit Care Med 1999;160(3): 950-960.

42. Pisarri TE, Yu J, Coleridge HM, Coleridge JC. Background activity in pulmonary vagal C-fibers and its effects on breathing. Respir Physiol 1986;64(1):29-43.

43. Sorichter S, Puschendorf B, Mair J. Skeletal muscle injury induced by eccentric muscle action: muscle proteins as markers of muscle fiber injury. Exerc Immunol Rev 1999;5(1):5-21.

44. Leung P, Jubran A, Tobin MJ. Comparison of assisted ventilator modes on triggering, patient effort, and dyspnea. Am J Respir Crit Care Med 1997;155(6):1940-1948.

45. Jaber S, Delay JM, Matecki S, Sebbane M, Eledjam JJ, Brochard L. Volume-guaranteed pressure-support ventilation facing acute changes in ventilatory demand. Intensive Care Med 2005;31(9): 1181-1188.

46. Jaber S, Sebbane M, Verzilli D, Matecki S, Wysocki M, Eledjam JJ, Brochard L. Adaptive support and pressure support ventilation behavior in response to increased ventilatory demand. Anesthesiology 2009;110(3):620-627.

47. Hess DR. Ventilator waveforms and the physiology of pressure support ventilation. Respir Care 2005;50(2):166-183; discussion 183-186.

48. Murata S, Yokoyama K, Sakamoto Y, Yamashita K, Oto J, Imanaka $\mathrm{H}$, Nishimura M. Effects of inspiratory rise time on triggering work load during pressure-support ventilation: a lung model study. Respir Care 2010;55(7):878-884.

49. Yamada Y, Du HL. Analysis of the mechanisms of expiratory asynchrony in pressure support ventilation: a mathematical approach. J Appl Physiol 2000;88(6):2143-2150.

50. Bonetto C, Caló MN, Delgado MO, Mancebo J. Modes of pressure delivery and patient-ventilator interaction. Respir Care Clin N Am 2005;11(2):247-263.

51. Du HL, Amato MB, Yamada Y. Automation of expiratory trigger sensitivity in pressure support ventilation. Respir Care Clin N Am 2001;7(3):503-507.

52. MacIntyre NR, Ho LI. Effects of initial flow rate and breath termination criteria on pressure support ventilation. Chest 1991;99(1): 134-138.

53. Tokioka H, Tanaka T, Ishizu T, Fukushima T, Iwaki T, Nakamura Y, Kosogabe Y. The effect of breath termination criterion on breathing patterns and the work of breathing during pressure support ventilation. Anesth Analg 2001;92(1):161-165.

54. Chiumello D, Polli F, Tallarini F, Chierichetti M, Motta G, Azzari $\mathrm{S}$, et al. Effect of different cycling-off criteria and positive endexpiratory pressure during pressure support ventilation in patients with chronic obstructive pulmonary disease. Crit Care Med 2007; 35(11):2547-2552.

55. Chiumello D, Pelosi P, Taccone P, Slutsky A, Gattinoni L. Effect of different inspiratory rise time and cycling off criteria during pressure support ventilation in patients recovering from acute lung injury. Crit Care Med 2003;31(11):2604-2610.

56. Kondili E, Xirouchaki N, Georgopoulos D. Modulation and treatment of patient-ventilator dyssynchrony. Curr Opin Crit Care 2007; 13(1):84-89.

57. Georgopoulos D, Prinianakis G, Kondili E. Bedside waveforms interpretation as a tool to identify patient-ventilator asynchronies. Intensive Care Med 2006;32(1):34-47.

58. Fernández-Pérez ER, Hubmayr RD. Interpretation of airway pressure waveforms. Intensive Care Med 2006;32(5):658-659.

59. Parthasarathy S, Jubran A, Tobin MJ. Assessment of neural inspiratory time in ventilator-supported patients. Am J Respir Crit Care Med 2000;162(2 Pt 1):546-552. 


\section{ASYNCHRONY AND DYSPNEA}

60. Parthasarathy S, Jubran A, Tobin MJ. Cycling of inspiratory and expiratory muscle groups with the ventilator in airflow limitation. Am J Respir Crit Care Med 1998;158(5 Pt 1):1471-1478.

61. Younes M, Brochard L, Grasso S, Kun J, Mancebo J, Ranieri M, et al. A method for monitoring and improving patient: ventilator interaction. Intensive Care Med 2007;33(8):1337-1346.

62. Robinson BRH, Blakeman TC, Toth P, Hanseman DJ, Mueller E, Branson RD. Patient ventilator asynchrony in a traumatically injured population. Respir Care 2013 [Epub ahead of print]

63. Chen CW, Lin WC, Hsu CH, Cheng KS, Lo CS. Detecting ineffective triggering in the expiratory phase in mechanically ventilated patients based on airway flow and pressure deflection: feasibility of using a computer algorithm. Crit Care Med 2008; 36(2):455-461.

64. Mulqueeny Q, Redmond SJ, Tassaux D, Vignaux L, et al. Automated detection of asynchrony in patient-ventilator interaction. Conf Proc IEEE Eng Med Biol Soc 2009;2009:5324-5327.

65. Mulqueeny Q, Ceriana P, Carlucci A, Fanfulla F, Delmastro M, Nava S. Automatic detection of ineffective triggering and double triggering during mechanical ventilation. Intensive Care Med 2007; 33(11):2014-2018.

66. Blanch L, Sales B, Montanya J, Lucangelo U, Garcia-Esquirol O, Villagra A, et al. Validation of the BetterCare system to detect ineffective efforts during expiration in mechanically ventilated patients: a pilot study. Intensive Care Med 2012;38(5):772-780. Erratum in: Intensive Care Med 2013;39(2):341.

67. Cuvelier A, Achour L, Rabarimanantsoa H, Letellier C, Muir JF, Fauroux B. A noninvasive method to identify ineffective triggering in patients with noninvasive pressure support ventilation. Respiration 2010;80(3):198-206.

68. Vignaux L, Vargas F, Roeseler J, Tassaux D, Thille AW, Kossowsky MP, et al. Patient-ventilator asynchrony during non-invasive ventilation for acute respiratory failure: a multicenter study. Intensive Care Med 2009;35(5):840-846.

69. Miyoshi E, Fujino Y, Uchiyama A, Mashimo T, Nishimura M. Effects of gas leak on triggering function, humidification, and inspiratory oxygen fraction during noninvasive positive airway pressure ventilation. Chest 2005;128(5):3691-3698.

70. Borel JC, Sabil A, Janssens JP, Couteau M, Boulon L, Levy P, et al. Intentional leaks in industrial masks have a significant impact on efficacy of bilevel noninvasive ventilation: a bench test study. Chest 2009;135(3):669-677.

71. Vignaux L, Tassaux D, Jolliet P. Performance of noninvasive ventilation modes on ICU ventilators during pressure support: a bench model study. Intensive Care Med 2007;33(8):1444-1451.

72. Ferreira JC, Chipman DW, Hill NS, Kacmarek RM. Bilevel vs ICU ventilators providing noninvasive ventilation: effect of system leaks: a COPD lung model comparison. Chest 2009;136(2): 448-456.

73. Costa R, Navalesi P, Spinazzola G, Ferrone G, Pellegrini A, Cavaliere $\mathrm{F}$, et al. Influence of ventilator settings on patient-ventilator synchrony during pressure support ventilation with different interfaces. Intensive Care Med 2010;36(8):1363-1370.

74. Branson RD, Gentile MA. Is humidification always necessary during noninvasive ventilation in the hospital? Respir Care 2010;55(2): 209-216; discussion 216.

75. Lellouche F, Maggiore SM, Deye N, Taillé S, Pigeot J, Harf A, et al. Effect of the humidification device on the work of breathing during noninvasive ventilation. Intensive Care Med 2002; 28(11):1582-1589.

76. Jaber S, Chanques G, Matecki S, Ramonatxo M, Souche B, Perrigault PF, et al. Comparison of the effects of heat and moisture exchangers and heated humidifiers on ventilation and gas exchange during non-invasive ventilation. Intensive Care Med 2002;28(11): 1590-1594.

77. Parthasarathy S, Tobin MJ. Effect of ventilator mode on sleep quality in critically ill patients. Am J Respir Crit Care Med 2002; 1:166(11):1423-1429.

78. Meza S, Mendez M, Ostrowski M, Younes M. Susceptibility to periodic breathing with assisted ventilation during sleep in normal subjects. J Appl Physiol 1998;85(5):1929-1940.

79. Fanfulla F, Taurino AE, Lupo ND, Trentin R, D'Ambrosio C, Nava $\mathrm{S}$. Effect of sleep on patient/ventilator asynchrony in patients undergoing chronic non-invasive mechanical ventilation. Respir Med 2007;101(8):1702-1707.

80. Bosma K, Ferreyra G, Ambrogio C, Pasero D, Mirabella L, Braghiroli A, et al. Patient-ventilator interaction and sleep in mechanically ventilated patients: pressure support versus proportional assist ventilation. Crit Care Med 2007;35(4):1048-1054.

81. Delisle S, Ouellet P, Bellemare P, Tétrault JP, Arsenault P. Sleep quality in mechanically ventilated patients: comparison between NAVA and PSV modes. Ann Intensive Care 2011;28;1(1):42.

82. Córdoba-Izquierdo A, Drouot X, Thille AW, Galia F, Roche-Campo F, Schortgen F, et al. Sleep in hypercapnic critical care patients under noninvasive ventilation: conventional versus dedicated ventilators. Crit Care Med 2013;41(1):60-68.

83. Toublanc B, Rose D, Glérant JC, Francois G, Mayeux I, Rodenstein D, Jounieaux V. Assist-control ventilation vs low levels of pressure support ventilation on sleep quality in intubated ICU patients. Intensive Care Med 2007;33(7):1148-1154.

84. Alexopoulou C, Kondili E, Vakouti E, Klimathianaki M, Prinianakis G, Georgopoulos D. Sleep during proportional-assist ventilation with load-adjustable gain factors in critically ill patients. Intensive Care Med 2007;33(7):1139-1147.

85. Anzueto A, Peters JI, Tobin MJ, de los Santos R, Seidenfeld JJ, Moore G, et al. Effects of prolonged controlled mechanical ventilation on diaphragmatic function in healthy adult baboons. Crit Care Med 1997;25(7):1187-1190.

86. Yang L, Luo J, Bourdon J, Lin MC, Gottfried SB, Petrof BJ. Controlled mechanical ventilation leads to remodeling of the rat diaphragm. Am J Respir Crit Care Med 2002;166(6):1135-1140.

87. Le Bourdelles G, Viires N, Boczkowski J, Seta N, Pavlovic D, Aubier M. Effects of mechanical ventilation on diaphragmatic contractile properties in rats. Am J Respir Crit Care Med 1994;149(10): 1539-1544.

88. Radell PJ, Remahl S, Nichols DG, Eriksson LI. Effects of prolonged mechanical ventilation and inactivity on piglet diaphragm function. Intensive Care Med 2002;28(3):358-364.

89. Vassilakopoulos T, Petrof BJ. Ventilator-induced diaphragmatic dysfunction. Am J Respir Crit Care Med 2004;169(2):336-341.

90. Levine S, Nguyen T, Taylor N, Friscia ME, Budak MT, Rothenberg $\mathrm{P}$, et al. Rapid disuse atrophy of diaphragm fibers in mechanically ventilated humans. N Engl J Med 2008;358(13):1327-1335.

91. Levine S, Biswas C, Dierov J, Barsotti R, Shrager JB, Nguyen T, et al. Increased proteolysis, myosin depletion, and atrophic AKTFOXO signaling in human diaphragm disuse. Am J Respir Crit Care Med 2011;183(4):483-490.

92. Hermans G, Agten A, Testelmans D, Decramer M, Gayan-Ramirez G. Increased duration of mechanical ventilation is associated with decreased diaphragmatic force: a prospective observational study. Crit Care 2010;14(4):R127.

93. Jaber S, Petrof BJ, Jung B, Chanques G, Berthet JP, Rabuel C, et al. Rapidly progressive diaphragmatic weakness and injury during mechanical ventilation in humans. Am J Respir Crit Care Med 2011; 183(3):364-371.

94. Hussain SN, Mofarrahi M, Sigala I, Kim HC, Vassilakopoulos T, Maltais F, et al. Mechanical ventilation-induced diaphragm disuse 
in humans triggers autophagy. Am J Respir Crit Care Med 2010; 182(11):1377-1386.

95. Papazian L, Forel JM, Gacouin A, Penot-Ragon C, Perrin G, Loundou A, et al. Neuromuscular blockers in early acute respiratory distress syndrome. N Engl J Med 2010;16:363(12):1107-1116.

96. Tobin MJ. Dyspnea. Pathophysiologic basis, clinical presentation and management. Arch Intern Med 1990;150(8):1604-1613.

97. Shiber JR, Santana J. Dyspnea. Med Clin North Am 2006;90(3): 453-479.
98. Knebel AR, Janson-Bjerklie SL, Malley JD, Wilson AG, Marini JJ. Comparison of breathing comfort during weaning with two ventilatory modes. Am J Respir Crit Care Med 1994;149(1):14-18.

99. Schmidt M, Demoule A, Polito A, Porchet R, Aboab J, Siami S, et al. Dyspnea in mechanically ventilated critically ill patients. Crit Care Med 2011;39(9):2059-2065.

100. Perren A, Previsdomini M, Llamas M, Cerutti B, Györik S, Merlani G, Jolliet P. Patients' prediction of extubation success. Intensive Care Med 2010;36(12):2045-2052.

\section{Discussion}

Kacmarek: Rich, in that French study you showed on dyspnea, ${ }^{1}$ did they find any correlation between dyspnea and the level of asynchrony? I assume that everything they did to fix the dyspnea would have caused great asynchrony. Was there a direct, indirect, or no relationship between dyspnea and asynchrony?

Branson: From my recollection, there was no relationship.

Kacmarek: They didn't report it?

Branson: It was reported, but there was no difference.

Hess: Bob raises an important point, which is whether there is a relationship between asynchrony and dyspnea. I don't think we know very well what that relationship is. In that study ${ }^{1}$ I thought it was interesting that they found that anxiety had a greater relationship to dyspnea than the ventilator settings. Maybe the approach we should be taking is dealing with the patient's anxiety rather than making a lot of manipulations of the ventilator. In support of that, in the same study only in a third of the patients were they able to adjust the ventilator so that the patient's dyspnea improved.

Branson: Right. Even though they're adjusting the ventilator, they're not getting any relief of dyspnea. They did get relief for some patients, enough to change the dyspnea visual analog scale score, which is essentially an anxiety scale. Adjusting the ventilator settings decreased the visual analog score by $1 \mathrm{~cm}$ in only $35 \%$ of patients. Sometimes there's nothing the ventilator can do about it.

MacIntyre: If PAV [proportional assist ventilation] is triggered by the patient's inspiratory effort and flow, why should it trigger better than pressure support using a flow trigger?

Branson: It doesn't: PAV does not perform any function until after the breath is initiated.

MacIntyre: You showed fewer asynchronies, which means fewer missed breaths.

Branson: The fewer asynchronies in PAV is usually due to the lower $V_{T}$ and better matching of neural inspiratory time and ventilator inspiratory time, less auto-PEEP, and therefore fewer missed triggers. But you're right: if you have auto-PEEP, there's nothing PAV can do about it. Again, I'm not necessarily a proponent or detractor of either technique. PAV will help you in some patients, but if you can't get rid of auto-PEEP or the leaks, then NAVA [neutrally adjusted ventilator assist] is the next logical step to getting rid of those problems. NAVA doesn't care what the auto-PEEP is, but then you have the extra expense associated with NAVA and you have to place the catheter.

Marini: Rich, one study I don't think you mentioned was from Strøm, in Denmark, where they didn't use any sedation, just analgesia. ${ }^{2}$ They were able to coast through a lot of the acute respiratory failure just using analge- sia. Has anybody looked at the discomfort of the tube, not the ventilator pattern? When I personally have been intubated awake, the pain and discomfort of the tube was the main thing I was worried about. If you ask patients what they complain about, they frequently point to the tube. To prevent throat pain you tend to limit the size of the breath you take, and you may fight the ventilator because of the discomfort there. That seems a fruitful area to look at.

Branson: I agree. A recent study looked at depth of sedation on the first day of ventilatory support and longterm outcome and duration of mechanical ventilation. ${ }^{3}$ It turned out that when we have these patients come in very sick, and we feel we've got to get them under control, and we give them a big dose of sedation and keep them down for a day, they do much worse than if we just paralyze them until we determine the pathophysiology and use less sedation. So I agree that sedation has a lot to do with it.

Kallet: I think what is particularly helpful, in terms of cutting to the chase in dealing with asynchrony, is something I credit to my old medical director, Dick Schlobohm. Back in the early 1980s he had us do what, for lack of a better term, might be called a diagnostic CPAP trial. If someone's fighting the ventilator, put them on $100 \%$ if necessary, keep the PEEP where it is, put them on CPAP, then look at the graphics: what is the $\mathrm{V}_{\mathrm{T}}$ they're trying to achieve, what is their peak inspiratory flow and flow pattern, and how variable is it? Is it every breath, every other breath, or every 
10-12 breaths? And then make a decision on how to address the problem.

Are you going to match or even exceed that breathing pattern to try to make the patient comfortable? If so, what's the plateau pressure and what's the risk of VILI [ventilator-induced lung injury] by doing so? Is that greater than or less than the risk of paralyzing the patient or using a lot of sedation? It's an efficient way of letting patients declare themselves, it reinforces the most fundamental concepts regarding asynchrony, and it clearly focuses clinicians on trying to balance these competing problems. I don't think we're very good at this; we're too focused on the ventilator modes and adjustments. We end up trying to chase the patient.

Marini: That's a valid point, Rich. You should look at the first couple breaths after you make the switch. Just like with SIMV, the patient doesn't change their effort much for the first breath or two. Then if they get an SIMV breath, they get a deep breath and actually down-regulate their breathing 2 or 3 breaths down the line, which may result in auto-PEEP during a big breath, but the deeper breath also causes less effort by the patient 2 breaths down the line, so to speak. So these neural interactions have a time component as well.

MacIntyre: To cut to the chase here, does anybody in this room believe that SIMV still has a role? Let the record show, I don't see a hand.

Branson: We still use SIMV: it depends on the surgeon's or the intensivist's decision. But at a meeting with Scott Epstein, I asked him how many of his patients are on SIMV, and he said none: they never use SIMV. But then the paper gets published and $70 \%$ of the patients in the de Wit study were on SIMV. ${ }^{4}$ I think we all should see what's actually happening, not just guess what's happening.
MacIntyre: I didn't ask if are you using it: I asked whether there was good reason to use it.

Marini: Occasionally I think there is: for the deeper breaths to re-expand any lung units that happen to be collapsed because you're not using enough PEEP, or whatever. Also, variability and depth of breathing may not necessarily be bad: healthy folks do it all the time, and it has been suggested as helping with gas exchange. There may be reason to use intermittent deep breaths in certain situations.

MacIntyre: What you're really describing, though, is perhaps a sigh breath interspersed with the variable $\mathrm{V}_{\mathrm{T}}$ and flows that you might get with, say, pressure support.

Marini: Yes, a deeper breath.

Kacmarek: What you really are describing is that we should use modes that follow what the patient wants to do, instead of modes where we force the patient to follow the way we set the ventilator. I'd add to that that we should set PEEP properly so that we don't have to worry about collapse at end-exhalation. We should encourage modes that improve asynchrony because they don't force a pattern on the patient, but instead allow the patient to select the pattern their ventilatory center establishes. I can't support SIMV as an approach to ventilation, but sometimes we use it because it seems to be the best alternative we have available. It still is not, in my opinion, an appropriate selection.

Marini: I seldom use it, but there is an argument for using it.

Schmidt: The argument that we should provide the ventilatory support the patient wants might sometimes be harmful, for example, if the patient wants a 2-liter tidal volume. I'm exaggerating, obviously, but should we let the patient injure his or her own lung? I have a problem with this. For example, it has been documented that the early use of pressure support in ARDS might be injurious to the lung; the ventilation the patient desires might be harmful.

Kallet: This is particularly sacrilegious coming from someone who's as strong of an ARDS Network supporter as I am, but when someone is acutely in distress and they can't get enough air after, let's say, suctioning, I don't think it's horrible for a minute or so to let the person catch their breath. And maybe a touch of sedative to calm them down if they feel like they're suffocating. I think sometimes we over-sedate patients because we won't even give them a couple of breaths to try to relieve their dyspnea, but instead we force them to breathe at 5 or $6 \mathrm{~mL} / \mathrm{kg}$. It's a hard thing to judge, I know, but with issues of excessive sedation in the ICU it's something we might need to consider.

Secondly, I think in some cases of respiratory distress, when the patient has a monotonous breathing demand, giving them a constant signal, whether it's a constant pressure or constant volume, may actually, over time, give them something to synchronize with. I think this might be preferable to this chaotic situation with closed-loop ventilation where the patient is out of synchrony with the ventilator and the patient is trying to adapt to the ventilator and the ventilator is trying to adapt to the patient. There's not a clear answer, but I think we need to think more in depth about this.

Kacmarek: Uli, the potential problem you described when allowing the patient to do what the ventilatory center dictates just does not happen! When you put a critically ill patients on CPAP and allow them to breathe on their own, they never take a 2-liter $\mathrm{V}_{\mathrm{T}}$ unless drug-induced.

Kallet: If they're extremely acidoticand have good muscle tone, they can 
sometimes generate very high pressures. If they're really acidotic, the brain tells them to breathe with a Kussmaul pattern. I see quite a few patients who can still inhale $900 \mathrm{~mL}$ or more, despite low chest compliance.

Kacmarek: The patient you describe needs to be controlled. My point is that most patients, particularly patients with ARDS, if allowed to control their ventilatory pattern, select a small $\mathrm{V}_{\mathrm{T}}$ and a rapid breathing frequency. You rarely see somebody choosing the huge $\mathrm{V}_{\mathrm{T}}$ you're talking about.

Schmidt: What about a young trauma patient?

Kacmarek: A young trauma patient is different because they have to be sedated. No matter what ventilation mode you choose, they may not be in the physiologic condition to be allowed to breathe spontaneously. If you look at the data on PAV or NAVA, most patients allowed to select their own ventilator pattern will choose a smaller $\mathrm{V}_{\mathrm{T}}$ than we would choose, and they will generally choose a more rapid breathing frequency than we would choose. Obviously, there are exceptions, but the vast majority of critically ill patients chose a rapid shallow ventilatory pattern.

Gajic: I'll again bring up the timing issue. I think it's a very big difference between early critical illness-and I mean the first 24 hours, not a week. What you do during the first 24 hours, after optimizing everything and preventing the rapid downward spiral of organ dysfunction, is extremely important. Days later the system appears to be less responsive to outside manipulation. Forcing sedation and paralysis during later stages of critical illness is unlikely to be beneficial. For those patients I don't think it matters if you have every fifth breath double stacking, or if they take large spontaneous tidal volumes. Some of these patients have central hyperventilation.
I am not aware of any evidence that this is detrimental by itself. I think the timing is very important when we talk about these things.

Kacmarek: You gave me the impression with that answer that every patient you intubate acutely you take over and do controlled ventilation at the onset for a period of time, regardless of what the reason for intubation is. Do you take over everybody with controlled ventilation and paralyze for a period?

Gajic: Not everybody: only those intubated for shock and/or acute hypoxemic respiratory failure.

Kacmarek: OK, agreed.

MacIntyre: One outcome I think would be interesting would be a measurement of sedation needs.

Branson: The only studies that usually measure sedation needs are the ones associated with APRV [airway pressure release ventilation], for whatever reason ${ }^{5,6}$ : mostly studies in postoperative cardiac cases. They've measured down to how many Euros they spend on the drugs for sedating and hemodynamic support, but they're usually comparing it to what we would all consider controlled ventilation.

MacIntyre: So the control group is suspect under those conditions.

Branson: Born and raised on SIMV, in the Downs ${ }^{7}$ and Kirby ${ }^{8}$ era, I remember when patients went on SIMV who had hypoxemic respiratory failure and normal ventilatory mechanics: the 22-year-old trauma patient who was shot in the liver and had his blood replaced 4 times. Those patients went on a high level of PEEP, and as John Marini described, got a breath like a sigh breath. the era of lung protection SIMV has to be rethought. In the 1970s SIMV was used with a large tidal vol- ume $(700-800 \mathrm{ml})$, and this acted like a sigh to reduce atelectasis. Today, if the mandatory breath is $400 \mathrm{~mL}$, the same effect will not be seen. John, I'm glad you're here, because I could never get any traction on this with Neil.

MacIntyre: You still haven't.

Branson: If the average breathing frequency in the ARDS Network study was 35 breaths/min-I figured this out one time: how many breaths is that in a day? $35 \times 1,440=$ about 50,000 breaths a day. Go back to Kirby and Downs Chest paper7: in their high PEEP or super PEEP group the patients were on an IMV [intermittent mandatory ventilation] rate of 4 breaths/min $(4 \times 1,440=5,600)$, so they get nowhere near the number of breaths. And if lung injury is not only from how big the stretch is, but how often it is-I'm just being controversial here, not saying we should all go home and do this-how do we know it wouldn't be different?

Kacmarek: We have no idea. And we did the same thing years ago, but those patients were working their butts off during those spontaneous breaths, so their transpulmonary pressures could have been huge, even though they did not receive frequent mandatory breathes. If you go back even further as to why SIMV was developed, it was because the only mode we had on ventilators was controlled mechanical ventilation. It was to allow patients to interact with the ventilator, which we could not do back in the late 1960s and early 1970s. The reason was simply the lack of technology at the time, which is why, when I look at today's capabilities, I think there's no need to continue a mode that was developed simply to allow us to do something that we can do more effectively and efficiently with today's technology.

Branson: So what do you think about ASV [adaptive support ventilation]? 
Kacmarek: I think it may have a place. We don't totally know yet about it, and it depends how it's applied and in what particular settings. During controlled ventilation it seems to work very well, but we need more data during assisted ventilation.

Branson: ASV is SIMV plus pressure support or SIMV plus volume support. We're all getting greyer at these meetings, but, from my standpoint, patients seem to tolerate a lot of what we do to them, which is good. We've got hospitals that use only APRV, hospitals that use only pressure controlled continuous mandatory ventilation, and hospitals that use only volume controlled continuous mandatory ventilation, and for the most part patients have similar good outcomes. These are academic centers where the experts are at the bedside helping fix these problems. And maybe that's why there's no real difference in outcomes. Maybe we need to start addressing the average hospital where Dr Marini doesn't work and see what happens there.

Hess: The tendency of most patients is to get better despite what we do to them.

Branson: Thank goodness.

\section{REFERENCES}

1. Schmidt M, Demoule A, Polito A, Porchet R, Aboab J, Siami S, et al. Dyspnea in mechanically ventilated critically ill patients. Crit Care Med 2011;39(9):2059-2065.

2. Strøm T, Martinussen T, Toft P. A protocol of no sedation for critically ill patients receiving mechanical ventilation: a randomized trial. Lancet 2010;375(9713): 475-480.

3. Shehabi Y, Bellomo R, Reade MC, Bailey M, Bass F, Howe B, et al; Sedation Practice in Intensive Care Evaluation (SPICE) Study Investigators; ANZICS Clinical Trials Group. Early intensive care sedation pre- dicts long-term mortality in ventilated critically ill patients. Am J Respir Crit Care Med 2012;186(8):724-731.

4. de Wit M, Pedram S, Best AM, Epstein SK. Observational study of patientventilator asynchrony and relationship to sedation level. J Crit Care 2009;24(1): 74-80.

5. Varpula T, Valta P, Niemi R, Takkunen O, Hynynen M, Pettilä VV. Airway pressure release ventilation as a primary ventilatory mode in ARDS. Acta Anaesthesiol Scand 2004;48(6):722-731.

6. Putensen C, Zech S, Wrigge H, Zinserling J, Stüber F, Von Spiegel T, Mutz N. Longterm effects of spontaneous breathing during ventilatory support in patients with acute lung injury. Am J Respir Crit Care Med 2001;164(1):43-49.

7. Kirby RR, Downs JB, Civetta JM, Modell JH, Dannemiller FJ, Klein EF, Hodges M. High level positive end expiratory pressure (PEEP) in acute respiratory insufficiency. Chest 1975;67(2):156-163.

8. Kirby RR, Perry JC, Calderwood HW, Ruiz BC, Lederman DS. Cardiorespiratory effects of high PEEP. Anesthesiology 1975; 43(5):533-559.

This article is approved for Continuing Respiratory Care Education credit. For information and to obtain your CRCE

(free to AARC members) visit

www.rcjournal.com 